\title{
Real-Time Water Quality Monitoring For Small Aquatic Area Using Unmanned Surface Vehicle
}

\author{
Alexander T. Demetillo \\ College of Engineering and Information Technology \\ Caraga State University \\ Butuan City, Philippines \\ atdemetillo@carsu.edu.ph
}

\author{
Evelyn B. Taboada \\ School of Engineering \\ University of San Carlos \\ Cebu City, Philippines \\ evelynbtaboada@gmail.com
}

\begin{abstract}
Most developing countries depend on conventional water quality monitoring methods which are usually expensive, complicated, and time-consuming. In recent years, stationary and portable water quality monitoring and a mobile surface vehicle have increased the utilization of on-site water measurements and monitoring. The first has the disadvantage of small coverage area while the second has its cost and operational complexity. This paper addresses these issues by placing materials and equipment used in fixed online water quality monitoring and using a customized and low-cost unmanned surface vehicle. The measurements are taken automatically on the equipment onboard the unmanned surface vehicle (USV), transmitted wirelessly to a PC-based remote station or nearby stations and saved there in a dedicated database. The overall system comprises a commercial water quality sensor, a GSM and Zigbee module for a wireless communication system, a low-cost mobility platform, and the location/positioning system. During testing, all captured data like water quality parameters, location, and other essential parameters were collated, processed and stored in a database system. Relevant information from the USV can be viewed on a smartphone or a computer. The USV was also tested to conduct unmanned water quality measurements using the preinputted navigation route which shows a good result in navigation and data transmission. Water bodies with calm water such as lakes and rivers can use the USV, in a stand-alone mode or as a part of a networked sensor system.
\end{abstract}

Keywords-unmanned surface vehicle; water quality monitoring; wireless transmission

\section{INTRODUCTION}

Because of population increase, industrialization and climate change, water demand is increasing at an alarming rate [1-3]. The sources of potable water are limited and vulnerable, thus the need for water quality monitoring in rivers, lakes, and other freshwater bodies is becoming a more pressing issue [4]. There is a growing demand to implement a mechanism to enhance the effectiveness of existing water quality monitoring methods. Mostly, water quality information gathering uses traditional or manual methods for various reasons ranging from lack of technology capacity, human resources and financial constraints [5-7]. These techniques or methodologies are usually accurate and inexpensive, but suffer from various disadvantages like the loss of vital information during transport, limited samples, and cost-effectiveness. They cannot perform real-time monitoring which could mitigate or prevent uncertain happenings in a particular area [8].

Nowadays, some advanced countries perform water quality monitoring using innovative technologies like utilizing an electrochemical sensor which can give water quality information in real-time [10-11], maximizing the advantages of recent technology by combining electrochemical sensors with wireless communication technology [11]. The system automatically senses data, transmits it to the notification node and will alarm if the parameters exceed their limits. Authors in [12] successfully demonstrated a method of deployment of a wireless sensor network with a mechanism to reduce traffic between base and remote stations for water quality monitoring wherein stationary stations could detect essential water parameters in real time. Gathered data were transmitted every five minutes to the base station through multi-hoop routing using a flooding routing protocol. However, the stationary platform also has the disadvantages of high cost of covering the whole study area [13], of provision of sensors in every sampling point and lack of mobility [14]. With these, the development of a mobile technology which will take advantage of the water quality monitoring capability of the stationary sensors and add mobility to enhance coverage, effectiveness, and efficiency of water monitoring is necessary [15]. USV technology with sensors on board could cater and house more research tools, thus improving the methods of water quality monitoring. Mobile vehicles in a marine or aquatic area could further increase the coverage of an automated water quality monitoring system with its ability to transfer from one location to another thus increasing the spatial and temporal measurement capability of the whole system. They can provide protection (housing and floatation) to the electronic equipment needed for monitoring and getting samples of the research area. With the advancement of computational ability, options for more monitoring equipment on board the USV increased through the utilization of new and innovative sampling methods $[17,18]$. This led to the increasing trend of using different approaches, design, and implementation in a mobile vehicle for WQMS endeavor.

Among many types of water surface vehicles for water and environmental monitoring, autonomous underwater vehicle

Corresponding author: Alexander T. Demetillo 
(AUV), unmanned surface vehicle (USV), and autonomous surface vehicle (ASV) are the most widely used [18]. ASV has the capabilities of large-area monitoring and worry-free unmanned navigation which is the ideal scenario for water quality monitoring, but comes with a high cost [19], while AUV also can be a handy tool, especially in dangerous areas, but has also a high price along with its complex operation and setup [20]. USVs offer the advantages of being less expensive and having simpler supervision compared to UAV, while they are easy to customize for a hybrid operation depending on the actual situation of the study area like an obstacle or floating objects which can be hardly detected using automation.

Several aquatic mobile vehicles have been developed for water quality monitoring with some enhancements like customized platforms to fit the actual conditions of the area [21], communication systems [22], and energy systems and mechanisms to cater the much-needed power of the vehicle $[24,25]$. Some known USV projects for water quality monitoring include bathymetric survey [25], data acquisition system on large fish and marine mammal movements [26], research on marine inhabitant activities [28-30], coastal environmental monitoring and pollutant tracking [13], emergency response and survey of damages [30], data acquisition and sampling for sea water and air [31]. Authors in [33] focused on the improvement of surface vehicle platforms, communications and coordination, propulsion, control and other crucial improvements. They covered basic important WQM parameters ranging from temperature to sodium with data being wirelessly transmitted to a nearby computer system for storage. Authors in [34] proposed another low-cost USV water quality monitoring, but with emphasis on inland water resources, while authors in [35] studied a multi-robot system approach to monitoring coastal waters, rivers, and lagoons in real-time with added features for the monitoring of heavy metal concentrations. Measurement of marine important parameters like partial pressure and sea-air fluxes of $\mathrm{CO}_{2}$ were conducted in [36]. The USV in [37] collects water samples in different water depths, places them in different water containers, and brings the samples for laboratory analysis. A remote-controlled watercraft with an automatic calibrator for sensors that need frequent calibration like $\mathrm{pH}$ was studied in [38] and low-cost bathymetry and depth monitoring in real time were performed in [25].

Small water bodies like lakes and rivers usually have shallow waters which are difficult and too expensive for an environmental ship to monitor. Operations in shallow waters require having a low draft and protection mechanism for the propellers. USV is able to operate in shallow waters with possible floating materials and plants such as water lilies, fish pens, and other barriers. With constraints for its total weight, it only allows a very minimalistic payload to be onboard the USV like a sensor, communication and navigational equipment with their electronics parts. The USV aims to provide a low-cost method capable of bringing information about water physicochemical parameters in real-time. This real-time monitoring can be an aid to the traditional or conventional methods of water quality monitoring which have high sensitivity, but seldom perform satisfyingly for budgetary constraints and other reasons. Instead, USV utilization would make up continuous monitoring systems essential in the investigation and characterization of some water quality parameters like $\mathrm{pH}$ and temperature which have very inconsistent characteristics. Received data can be further analyzed and may serve as input to decision making.

This study focuses on the design of an unmanned mobile vehicle for water quality monitoring with consideration of the actual requirements and scenarios of the target area which is Lake Mainit, Philippines. Its main features are its affordability and adaptability to the field of study.

\section{MATERIALS AND METHODS}

The primary goal of the USV is to give an alternative method in water quality monitoring in dangerous areas and high-risk jobs. To collect data in hard to reach areas [19], to improve the data collection frequency, which if done manually could lead to expensive and laborious endeavor. Figure 1 shows the diagram of the proposed system in which data collection is automated. Figure 2 shows the USV prototype during its first testing. Boat materials available in the area were used for creating its body and motor and its controllers are commercially available WQ sensors from Atlas Scientific ( $\mathrm{pH}$ and temperature) making this design ready for replication. Also, to make it affordable, open source software was utilized. This software is used to receive and accumulate data acquired from the onboard sensors of the USV as an input interface for navigational operation setup, and to download the predefined USV direction. The system is divided in four subsystems, namely USV platform, automated sensor system, application software, and a base station.

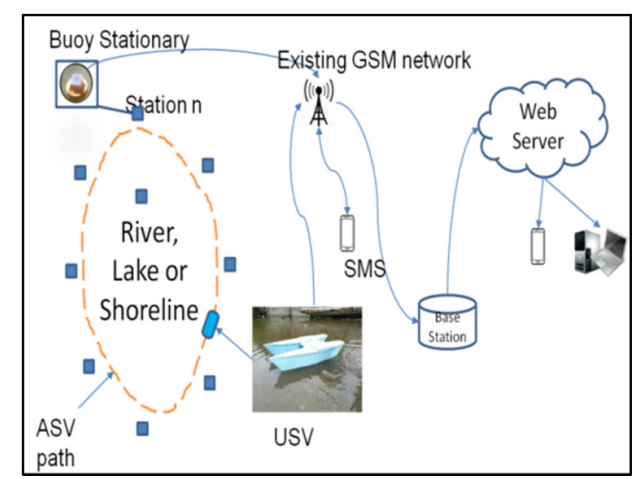

Fig. 1. Diagram of mobile water quality monitoring

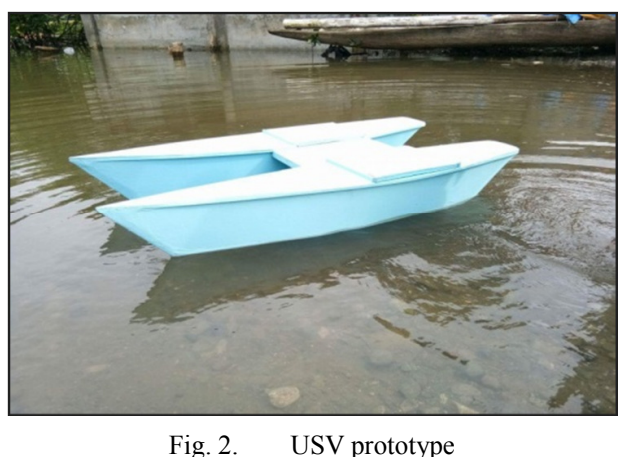




\section{A. Construction}

Most of the materials used in the catamaran-type USV are available online or in the local market. The main goal of this research is to build a floating and mobile platform that can perform water quality monitoring in a sizeable aquatic area that is too large for the deployment of stationary sensors and too risky and difficult for manual sampling. USV design considers affordability, replicability and flexibility to cater to an actual field situation. The USV was designed and built in the Center for Robotics, Automation and Fabrication Technology (CRAFT) of Caraga State University in Butuan City, Philippines. It is an enhancement of the previous project for WQM which uses buoy as floating material, but in a permanent location. The area to be covered is set to be $5 \mathrm{~km}^{2}$ per day with the need to sample/measure water in at least 1-meter depth. These requirements are in consideration with the area of the Lake Mainit of Caraga region in the Philippines where mining activities are rampant. These facts led to a consideration of a minimum speed of 1 nautical mile $(0.5 \mathrm{~m} / \mathrm{s})$, and a maximum weight of $40 \mathrm{~kg}$. A catamaran-type of construction was chosen for its proven stability on water, which allows easy control. The USV can be operated using remote control or can be automated depending on the location of the area and the distance it will cover. The operator might opt for remote-controlled operation if the area is small and there is a presence of an obstacle or floating materials or species that might destroy or damage the USV propeller, the casing or onboard sensors. The automatic operation fits with considerable area coverage with no obstruction or floating objects. The operator can design a mission plan and define its coordinates for the sampling location. With these, deployment makes data gathering unmanned and automated in dangerous and difficult to reach areas.

\section{B. Electronic Module}

In terms of electronic components, the USV system comprises of two subsystems: USV unit and ground control station with corresponding electronic equipment. The ground control station comprises of a computer system (laptop/PC) and wireless transceivers linking with the USV. The ground control has also the path/direction application program used in updating the USV path and pointing of sampling if needed. Communication module comprises of telemetry, Xbee, and RC modules. The data related to the mobility of the USV are catered by the Ardupilot using telemetry. XBee module is used to transmit the gathered data to the nearest station while the remote controller (RC) module is used for the manual navigation control of the USV. It used a customized mission planner using an open source program powered by Arduino IDE to control the navigational operation of the USV. For a continuous operation, a mission plan must be downloaded to the microcontroller before the start of the mission. The automated operation used a compass board and GPS module as a means to follow the predefined navigational route. Sensing of data is the same with the stationary sensor methodology. The sensor determines the value and after proper conditioning and boosting it will be transferred to the microcontroller for preprocessing and will be sent to the wireless transceiver for transmission to the nearest stations or pre-defined cellphone numbers. Wireless transmission is done through an Xbee technology for short distance and GSM/GPRS transceiver for long-distance transmission. Arduino IDE is the software used to configure the microcontroller (Arduino mega 2560), XBee short distance communication and GSM/GPS setup for long distance transmission. XBee module provides wireless connectivity to devices using end-point solutions. XBee uses IEEE 802.15.4 networking protocol which is common to low power clustering communication setups. For long distance transmission and reception of data a GSM module is used. It has a library which mimics an Arduino board to perform operations same as an ordinary GSM powered cellphone like receiving and sending messages and connect to the local telecommunication companies. The GSM/GPRS transceiver has a built-in modem that facilitates data transfer from a serial port to the GSM network. It will receive data at the controller by another Xbee. An open source program will process this data using Microsoft Visual Studio flat form to facilitate userfriendly display and storage.

A triple-axis magnetometer compass board HMC5883L (Honeywell) and a NEO-6M GPS Module (uBlox) control the navigation system of the USV, designed to cover all functions for unmanned operation using a pre-programmed mission plan. The body of the USV platform utilizes marine plyboard with painting to safeguard the USV onboard electronic components. A wooden material houses the battery and other electronic components and connected to $1.5 \mathrm{~m}$ (from head to tail) by $1 \mathrm{~m}$ wide catamaran boat type. The USV can carry a maximum payload of $40 \mathrm{~kg}$. Finally, the wireless transceiver and sensor calibration were completed before testing the whole system in the actual application.

The water sensor unit is the primary component of the mobile water quality monitoring system. In this research, it employed two sensors from the Atlas Scientific company for measuring $\mathrm{pH}$ and temperature. With the built-in flexibility of Arduino microcontroller, it can add more number of electrodes depending on the needs. $\mathrm{pH}$ and temperature sensors have their interface circuits which are also provided by the manufacturer. Only the temperature sensor is connected directly to the analog pin of the microcontroller. It utilized a customized motherboard to connect all electronic components to the microcontroller. Also, the board allows other modules and circuits, while having a feature to isolate the sensor individually and eliminate issues of noise. To maintain accuracy, electrodes are calibrated based on the manufacturer standards and using their own calibration solutions. The microcontroller unit is the main part of the USV and makes it unique among other aquatic mobile vehicles. It has pins which can expand its utilization. It comprises of a hardware microcontroller and a software program that guides the operation of the microcontroller with the rest of the USV parts. This research uses Arduino Mega 256, the most expandable Arduino microcontroller to accommodate capability and future expansion of the system. Same with the early variant of the Arduino microcontroller, it has an opensource electronics prototyping platform, flexible, easy-to-use hardware, and user friendly programming environment [39]. The USV preprocess the data using the preprogrammed commands downloaded to the microcontroller. The developed software program uploaded into the microcontroller memory sets the sensor node to measure the water quality parameter at 
predetermined time intervals. The data are always copied in an SD card before transmission as backup data storage.

\section{Software}

The software for all USV electronic modules controlled by the microcontroller is written in Arduino IDE while Microsoft Visual Studio (IDE) was used to develop the Windows application that interfaces the USV output to the computer systems in the base station. Figure 3 shows the flowchart of the USV software. It uses the Windows application to receive data from the serial port that connects the communication link of the USV. First, the microcontroller initializes all the components and waits for the GPS to be ready before it navigates using either the preprogrammed path or through remote control.

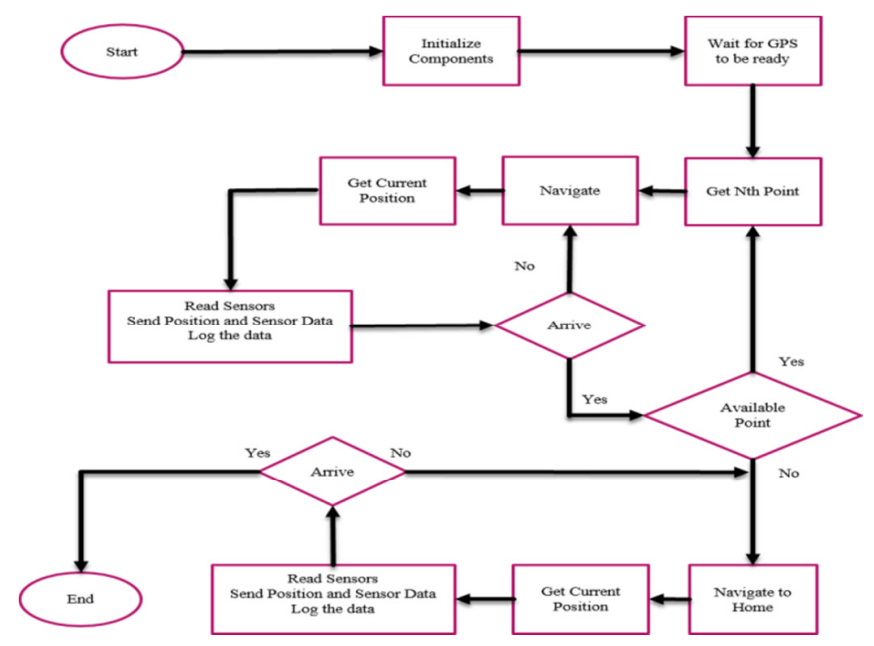

Fig. 3. USV program flowchart

For RC operation, all programming comes from manual input of the operator which converts a string of commands and processes by the microcontroller for execution like direction, points of sampling, etc. In the autonomous method, the microcontroller sets the destination points, navigates, gets the current position of the USV from the GPS, reads the sensors, and sends and logs data. With the destination point encoded, the microcontroller navigates until it reaches home location.

\section{USV Datalogger}

For easy data transfer from the USV to base station a data logger was designed. Figure 4 shows the software application interface for the USV which was developed using Visual Studio. It was designed in such a way that it will display the incoming data in a tabulated form. Also, it provides a mechanism of updating the path of the USV using a simple inputting of values through a graphical interface. The USV's time to stay and gather data before it will navigate or move to another location can change through this logger. All necessary inputs are displayed for the user to review.

\section{RESULTS AND DISCUSSION}

After a laboratory bench testing of the different parts of the system, the USV was assembled. Navigation trials were conducted in order to check if specifications were followed. A series of tests were also conducted for its autonomous navigation. Laboratory tests included measurements of the quality of communication between the control unit and the USV, and the interruption of the radio link. The results of the connection measurements conform to the minimum standards.

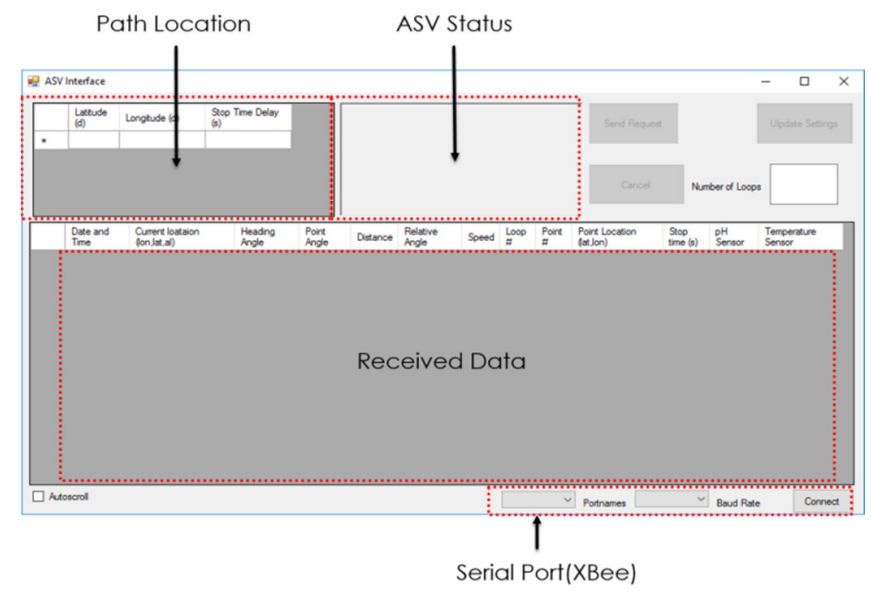

Fig. 4. USV interface application

\section{A. Navigation Testing}

Upon the construction of the vessel prototype, testing followed in the creek found inside the University campus. Maneuvering capabilities, vessel stability, and navigation speed were tested. The results of maneuvering capabilities and stability were outstanding since the catamaran was stable and could rotate almost around its axis. The average navigation speed was $1 \mathrm{knot}$, while $180^{\circ}$ turn was achieved in less than $15 \mathrm{~s}$. Also, testing the range of the radio link, stability, and behavior of the boat at some water disturbances that mimic small sea waves was conducted. Tests showed that the radio link range in the open sea is about $150 \mathrm{~m}$.

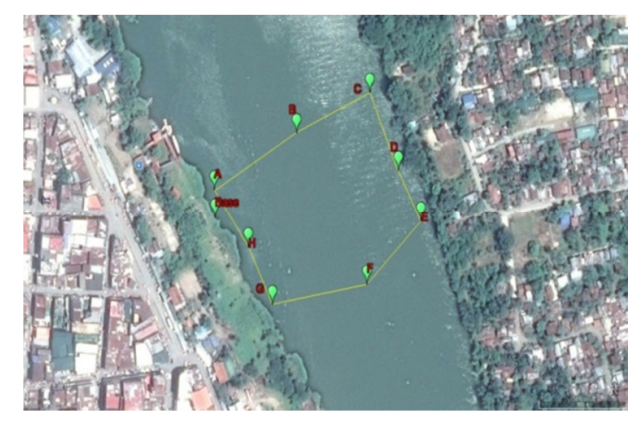

Fig. 5. USV's path

\section{B. WQM Sensor testing}

A calibration process was conducted to the electrochemical sensors in the lab for their accuracy and functionality. Calibration solution interface and isolation circuit from Atlas Scientific were utilized to calibrate and test the $\mathrm{pH}$ electrodes. For field testing, freshly calibrated electrodes from the lab were installed on the USV side platform. A series of final tests of the electronic component implemented were conducted before the 
actual operation. The configuration of the water quality sensor was the same with the one used in the laboratory. The USV was programmed to measure a minute after its arrival at the designated testing point or on the points/area where the operator wanted to make the measurement. Figure 5 shows the data received from the USV. It shows the effectivity of the system by accurately displaying important WQMS parameters, which include $\mathrm{pH}$, temperature, time, date etc. It validates that the system performs following the specifications of the electronic component and the USV delivers its primary function which is to protect components from water intrusion. The test also did not encounter a significant problem except the periodic GSM signal. The display works well on PCs, laptops, and smart mobile phones. With these, the onboard water sensor and its peripherals can provide the needed resources, thus giving stakeholders an alternative method on how to conduct water quality monitoring continuously.

\begin{tabular}{|c|c|c|c|}
\hline Date and Time & Current Location (lon, lat,al) & pH Sensor & Temperature Senso \\
\hline 8/5/2017 - 13:19:30 & $125.523757,8.971646,5.00$ & 7.122 & 30.367 \\
\hline 8/5/2017-13:19:31 & $125.523757,8.971645,5.00$ & 7.122 & 30.367 \\
\hline 8/5/2017 - 13:19:33 & $125.523757,8.971645,5.00$ & 7.122 & 30.367 \\
\hline 8/5/2017 - 13:19:34 & $125.523757,8.971645,5.00$ & 7.122 & 30.366 \\
\hline 8/5/2017--13:19:35 & $125.523757,8.971645,5.00$ & 7.121 & 30.366 \\
\hline 8/5/2017 - 13:19:36 & $125.523757,8.971644,5.00$ & 7.124 & 30.366 \\
\hline 8/5/2017-13:19:37 & $125.523757 .8 .971644,5.00$ & 7.121 & 30.365 \\
\hline 8/5/2017-13:19:39 & $125.523757,8.971644,5.00$ & 7.122 & 30.365 \\
\hline $8 / 5 / 2017-13: 19: 40$ & $125.523757 .8 .971644,5.00$ & 7.123 & 30.364 \\
\hline 8/5/2017 - 13:19:41 & $125.523757,8.971644,5.00$ & 7.123 & 30.364 \\
\hline 8/5/2017-13:19:42 & $125.523757,8.971643,5.00$ & 7.122 & 30.362 \\
\hline $8 / 5 / 2017-13: 19: 43$ & $125.523757,8.971643,5.00$ & 7.124 & 30.362 \\
\hline 8/5/2017 - 13:19:45 & $125.523757,8.971643,5.00$ & 7.123 & 30.362 \\
\hline 8/5/2017 - 13:19:46 & $125.523757,8.971642,5.00$ & 7.121 & 30.36 \\
\hline 8/5/2017 - 13:19:47 & $125.523757 .8 .971642,5.00$ & 7.121 & 30.36 \\
\hline $8 / 5 / 2017-13: 19: 48$ & $125.523757,8.971642,5.00$ & 7.122 & 30.36 \\
\hline 8/5/2017- -13:19:49 & 125.523757,8.971642,5.00 & 7.122 & 30.36 \\
\hline 8/5/2017--13:19:51 & $125.523757 .8 .971642,5.00$ & 7.122 & 30.36 \\
\hline 8/5/2017 - 13:19:52 & $125.523757,8.971642,5.00$ & 7.12 & 30.36 \\
\hline 8/5/2017 - 13:19:53 & $125.523750,8.971641,5.00$ & 7.121 & 30.36 \\
\hline 8/5/2017- 13:19:54 & $125.523750,8.971641,5.00$ & 7.12 & 30.36 \\
\hline 8/5/2017 - 13:19:55 & $125.523750,8.971641,5.00$ & 7.12 & 30.36 \\
\hline 8/5/2017 - 13:19:57 & 125.523750,8.971640,5.00 & 7.118 & 30.36 \\
\hline $8 / 5 / 2017-13: 19: 58$ & $125.523750,8.971640,5.00$ & 7.121 & 30.359 \\
\hline 8/5/2017- -13:19:59 & $125.523750,8.971639,5.00$ & 7.121 & 30.359 \\
\hline
\end{tabular}

Fig. 6. Sample of the output of the system

\section{CONCLUSIONS}

With changing water environment, the need for a low-cost and mobile method of measurement is increasing. In this research, the design and development of a low-cost mobile vehicle as a tool to carry water sensors and transmit their results wirelessly was successfully implemented. Utilization of easy to find sensors, locally available materials for the USV parts, and development of customized integrated software using open source technology are the main advantages of the system when compared with commercial USVs. Laboratory and on-site results show the USV's capability to conduct water quality monitoring in a lake and other small bodies of water. Temperature $\mathrm{pH}$, time and date were transmitted. In conclusion, this system has the potential to enhance reporting and information dissemination regarding the status of water quality.

\section{ACKNOWLEDGEMENT}

Authors wish to thank the scholarship funding given by the Department of Science and Technology through its Engineering Research and Development for Technology (ERDT) Program and the Caraga State University for allowing the use of its laboratory and equipment.

\section{REFERENCES}

[1] J. Heath, H. P. Binswanger, "Natural Resource Degradation Effects of Poverty and Population Growth are Largely Policy-induced: The case of Colombia", Environment and Development Economics, Vol. 1, No. 1, pp. $65-84,1996$

[2] W. Mo, H. Wang, J. M. Jacobs, "Understanding the influence of climate change on the embodied energy of water supply", Water Research, Vol. 95, pp. $220-229,2016$

[3] C. Dalin, N. Hanasaki, H. Qiu, D. L. Mauzerall, I. Rodriguez-Iturbe, "Water resources transfers through Chinese interprovincial and foreign food trade", Proceedings of the National Academy of Sciences, Vol. 111, No. 27, pp. 9774-9779, 2014

[4] M. V. Japitana, E. V. Palconit, A. T. Demetillo, M. E. C. Burce, E. B. Taboada, M. L. S. Abundo, "Integrated technologies for low cost environmental monitoring in the water bodies of the Philippines: A review", Nature Environment and Pollution Technology, Vol. 17, No. 4, pp. 1125-1137, 2018

[5] K. Kondratjevs, A. Zabasta, N. Kunicina, L. Ribickis, "Development of pseudo autonomous wireless sensor monitoring system for water distribution network", in: IEEE International Symposium on Industrial Electronics, pp. 1454-1458, IEEE, 2014

[6] N. Nasser, A. Ali, L. Karim, S. Belhaouari, "An efficient Wireless Sensor Network-based water quality monitoring system", ACS International Conference on Computer Systems and Applications, Ifrane, Morocco, May 27-30, 2013

[7] S. Silva, H. N. Nguyen, V. Tiporlini, K. Alameh, "Web based water quality monitoring with sensor network: Employing ZigBee and WiMax technologies", 8th International Conference on High-Capacity Optical Networks and Emerging Technologies, Riyadh, Saudi Arabia, December 19-21, 2011

[8] T. P. Lambrou, C. C. Anastasiou, C. G. Panayiotou, M. M. Polycarpou, "A Low-Cost Sensor Network for Real-Time Monitoring and Contamination Detection in Drinking Water Distribution Systems", IEEE Sensors Journal, Vol. 14, No. 8, pp. 2765-2772, 2014

[9] M. Simic, L. Manjakkal, K. Zaraska, G. M. Stojanovic, "TiO2 Based Thick Film pH Sensor”, IEEE Sensor Journals, Vol. 17, No. 2, pp. 248255, 2017

[10] E. Hoque, L. H. H. Hsu, A. Aryasomayajula, P. R. Selvaganapathy, P. Kruse, "Pencil-Drawn Chemiresistive Sensor for Free Chlorine in Water", IEEE Sensors Letters, Vol. 1, No. 4, pp. 1-4, 2017

[11] N. A. Cloete, R. Malekian, L. Nair, "Design of Smart Sensors for RealTime Water Quality Monitoring”, IEEE Access, Vol. 4, No. 9, pp. 39753990, 2016

[12] W. Y. Chung, J. H. Yoo, "Remote water quality monitoring in wide area", Sensors Actuators B: Chemical, Vol. 217, pp. 51-57, 2015

[13] W. Naeem, T. Xu, R. Sutton, A. Tiano, "The design of a navigation, guidance, and control system for an unmanned surface vehicle for environmental monitoring", Proc. IMeCHE, Vol. 222, No. M, pp. 67-79, 2008

[14] G. Hitz, F. Pomerleau, M. E. Garneau, C. Pradalier, T. Posch, J. Pernthaler, R. Y. Siegwart, "Autonomous Island Water Monitoring: Design and Application of a Surface Vessel", IEEE Robotics \&. Automation Magazine, Vol. 19, No. 1, pp. 62-72, 2012

[15] G. Ferri, A. Manzi, F. Fornai, F. Ciuchi, C. Laschi, "The HydroNet ASV, a Small-Sized Autonomous Catamaran for Real-Time Monitoring of Water Quality: From Design to Missions at Sea", IEEE Journal of Oceanic Engineering, Vol. 40, No. 3, pp. 710-726, 2015

[16] G. Ferri, M. Cococcioni, A. Alvarez, "Sampling on-demand with fleets of underwater gliders", 2013 MTS/IEEE OCEANS - Bergen, Bergen, Norway, June 10-14, 2013

[17] T. Huntsberger, G. Woodward, "Intelligent autonomy for unmanned surface and underwater vehicles", OCEANS'11 MTS/IEEE KONA, Waikoloa, USA, September 19-22, 2011

[18] J. E. Manley, "Unmanned Maritime Vehicles, 20 years of commercial and technical evolution", OCEANS 2016 MTS/IEEE Monterey, Monterey, USA, September 19-23, 2016 
[19] N. Wang, S. Lv, M. J. Er, W. H. Chen, "Fast and Accurate Trajectory Tracking Control of an Autonomous Surface Vehicle With Unmodeled Dynamics and Disturbances", IEEE Transactions on Intelligent Vehicles, Vol. 1, No. 3, pp. 230-243, 2016

[20] L. Paull, S. Saeedi, M. Seto, H. Li, "AUV navigation and localization: A review”, IEEE Journal of Oceanic Engineering, Vol. 39, No. 1, pp. 131149,2014

[21] B. Bayat, N. Crasta, A. Crespi, A. M. Pascoal, A. Ijspeert, "Environmental monitoring using autonomous vehicles: a survey of recent searching techniques", Current Opinion in Biotechnology, Vol. 45. pp. 76-84, 2017

[22] J. Sanchez-Garcia, J. M. Garcia-Campos, M. Arzamendia, D. G. Reina, S. L. Toral, D. Gregor, "A survey on unmanned aerial and aquatic vehicle multi-hop networks: Wireless communications, evaluation tools and applications", Computer Communications, Vol. 119, pp. 43-65, 2018

[23] A. Makhsoos, H. Mousazadeh, S. S. Mohtasebi, M. Abdollahzadeh, H. Jafarbiglu, E. Omrani, Y. Salmani, A. Kiapey, "Design, simulation and experimental evaluation of energy system for an unmanned surface vehicle”, Energy, Vol. 148, pp. 362-372, 2018

[24] H. Niu, Y. Lu, A. Savvaris, A. Tsourdos, "An energy-efficient path planning algorithm for unmanned surface vehicles", Ocean Engineering, Vol. 161, pp. 308-321, 2018

[25] H. Mousazadeh, J. Hamid, O. Elham, M. Farshid, K. Ali, S. Z. Yousef, M. Ashkana, "Experimental evaluation of a hydrography surface vehicle in four navigation modes", Journal of Ocean Engineering and Science, Vol. 2, No. 2, pp. 127-136, 2017

[26] C. A. Goudey, T. Consi, J. Manley, M. Graham, B. Donovan, L. Kiley, "A robotic boat for autonomous fish tracking", Marine Technology Society Journal, Vol. 32, No. 1, p. 47, 1998

[27] E. Fumagalli, M. Bibuli, M. Caccia, E. Zereik, F. DelBianco, L. Gasperini, G. Stanghellini, G. Bruzzone, "Combined acoustic and video characterization of coastal environment by means of unmanned surface vehicles", IFAC Proceedings Volumes, Vol. 19, No. 3, pp. 4240-4245, 2014

[28] L. Bittencourt, W. Soares-Filho, I. M. S. D. Lima, S. Pai, J. LailsonBrito Jr, L. M. Barreira, A. F. Azevedo, L. A. A.Guerra, "Mapping cetacean sounds using a passive acoustic monitoring system towed by an autonomous Wave Glider in the Southwestern Atlantic Ocean", Deep Sea Research Part I: Oceanographic Research Papers, Vol. 142, pp. 5868, 2018

[29] Y. Singh, S. Sharma, R. Sutton, D. Hatton, A. Khan, "A constrained A* approach towards optimal path planning for an unmanned surface vehicle in a maritime environment containing dynamic obstacles and ocean currents", Ocean Engineering, Vol. 169, pp. 187-201, 2018

[30] R. R. Murphy, E. Steimle, C. Griffin, C. Cullins, M. Hall, K. Pratt, "Cooperative use of unmanned sea surface and micro aerial vehicles at Hurricane Wilma", Journal of Field Robotics, Vol. 25, No. 3, pp. 164180,2008

[31] M. Caccia, R. Bono, G. Bruzzone, G. Bruzzone, E. Spirandelli, G. Veruggio, G. Capodaglio, A. M. Stortini, "SESAMO: An autonomous surface vessel for the study and characterization of the air-sea interface", IFAC Proceedings Volumes, Vol. 36, No. 21, pp. 259-264, 2003

[32] M. Blaich, S. Wirtensohn, M. Oswald, O. Hamburger, J. Reuter, "Design of a twin hull based USV with enhanced maneuverability", IFAC Proceedings Volumes, Vol. 9, No. 33, pp. 1-6, 2013

[33] J. Wiora, A. Kozyra, A. Wiora, "Towards automation of measurement processes of surface water parameters by a remote-controlled catamaran", Bulletin of the Polish Academy of Sciences Technical Sciences, Vol. 65, No. 3, pp. 351-359, 2017

[34] S. Siyang, T. Kerdcharoen, "Development of unmanned surface vehicle for smart water quality inspector", 2016 13th International Conference on Electrical Engineering/Electronics, Computer, Telecommunications and Information Technology (ECTI-CON), Chiang Mai, Thailand, June 28-July 1, 2016

[35] G. Ferri, A. Manzi, F. Fornai, B. Mazzolai, C. Laschi, F. Ciuchi, P. Dario, "Design, fabrication and first sea trials of a small-sized autonomous catamaran for heavy metals monitoring in coastal waters",
2011 IEEE International Conference on Robotics and Automation, Shanghai, China, May 9-13, 2011

[36] F. P. Chavez, J. Sevadjian, C. Wahl, J. Friederich, G. E. Friederich, "Measurements of pCO2and $\mathrm{pH}$ from an autonomous surface vehicle in a coastal upwelling system”, Deep Sea Research Part II: Topical Studies in Oceanography, Vol. 151, pp. 137-146, 2018

[37] F. Fornai, G. Ferri, A. Manzi, F. Ciuchi, F. Bartaloni, C. Laschi, "An Autonomous Water Monitoring and Sampling System for Small-Sized ASVs", IEEE Journal of Oceanic Engineering, Vol. 42, No. 1, pp. 5-12, 2017

[38] A. Kozyra, K. Skrzypczyk, K. Stebel, A. Rolnik, P. Rolnik, M. Kucma, "Remote controlled water craft for water measurement", Measurement, Vol. 111, pp. 105-113, 2017

[39] Y. A. Badamasi, "The working principle of an Arduino", 11th International Conference on Electronics, Computer and Computation, Abuja, Nigeria, September 29-October 1, 2014 